\title{
Investigation of the differences between deepening and intensification for 500-hpa cyclones in central and East Mediterranean region during warm season of the year
}

\author{
S. Spanos \\ University of Thessaly, Department of Agriculture School of Plant Production and Agricultural Environment, Volos, Greece
}

Received: 25 October 2005 - Revised: 22 December 2005 - Accepted: 23 January 2006 - Published: 17 February 2006

\begin{abstract}
The maximum deepening rate per cyclone track is determined by the maximum height drop at the center of the cyclone (500-hPa low) on the basis of all the 6-h successive steps in its life cycle. The geopotential height gradient is calculated over the entire low area and the calculation continued with the variation of the gradient in the successive steps. The maximum intensification rate per cyclone is then determined as the maximum increase of the gradient in the life cycle. Maximum deepening rate for the 500-hPa cyclones in the area does not exceed, on average, $12 \mathrm{gpm} / 6 \mathrm{~h}$. Maximum intensification which is $1.4 \mathrm{gpm} / 100 \mathrm{Km} * 6 \mathrm{~h}$ on average, occurs in the early stages of the cyclone's life cycle. This on the average happens approximately $9 \mathrm{~h}$ after the first time the low is detected. At the gulf of Genoa and the Adriatic Sea, cyclones usually show the maximum intensification after the maximum deepening. At Turkey's cyclogenesis area, however, this order is reversed. The spatial distributions of maximum intensification in the three sub-periods, indicate that it mainly occurs over Seas during late warm periods and over land during early and middle warm periods. Such a behavior underlines the role of low-level instability in cyclone development.
\end{abstract}

\section{Introduction}

Although deepening and intensification of systems are often considered as synonyms, they are different (Saucier, 1989). A cyclone may be deepening while weakening (cyclolysis), or it may be intensifying (cyclogenesis) and filling (Fig. 1). While deepening refers only to change of pressure height, intensification refers to the increase of the height gradient or the increase of circulation with time. Maximum values and the time of occurrence for these parameters characterize cyclones and their life cycles.

Correspondence to: S. Spanos

(seraf@in.gr)
Warm-dry period in the Mediterranean is characterized by the lack or restriction of the number of surface systems at the northern parts. Pressure gradients are weak and the systems are not easily identified. Upper level studies are therefore required. The number of published 500-hPa objective Climatologies is small (Bell and Bosart, 1989; Parker et al., 1989; Alberta et al., 1991) and not devoted to the Mediterranean. In Spanos et al. 2003, an objective 500-hPa cyclones detection and analysis was performed for the warm period (16 April to 15 October) of the year at the central and east Mediterranean region. In that work, the 40-year (1958-1997) NCEP/NCAR reanalysis gridded data of geopotential height with a $2.5^{\circ} \times 2.5^{\circ}$ spatial and a $6 \mathrm{~h}$ temporal resolution $(00: 00$, 06:00, 12:00, 18:00 UTC) were used. Lows were determined as local minima in each $3 \times 3$ matrix of geopotential height values within the area of investigation. A gradient criterion (Spanos et al., 2003) was also applied to exclude weak lows, which probably originate from the assimilation procedure. A variation of the "nearest neighbour" track algorithm (Trigo et al., 1999) was employed in the determination of tracks and the corresponding areas of cyclogenesis.

The present paper is based on that work, which is further extended to the investigation of deepening and intensification of cyclones within the investigation area (Fig. 2). The 6hsteps, which are followed in the evolution of a cyclone, are characterized as deepening or filling when the height varies by more than $10 \mathrm{gpm} / 6 \mathrm{~h}$. The maximum deepening rate per cyclone track is determined as the maximum height drop at the center of the cyclone from all 6-h successive steps in its life circle. The geopotential height gradient is calculated over the entire low area and the calculation is carried further with the variation of the gradient in the successive steps. They are similarly characterized as intensification or weakening steps when the gradient varies by more than $1 \mathrm{gpm} / 100 \mathrm{Km} * 6 \mathrm{~h}$. The maximum intensification rate per cyclone track is then determined as the maximum increase of the gradient during the life cycle. 


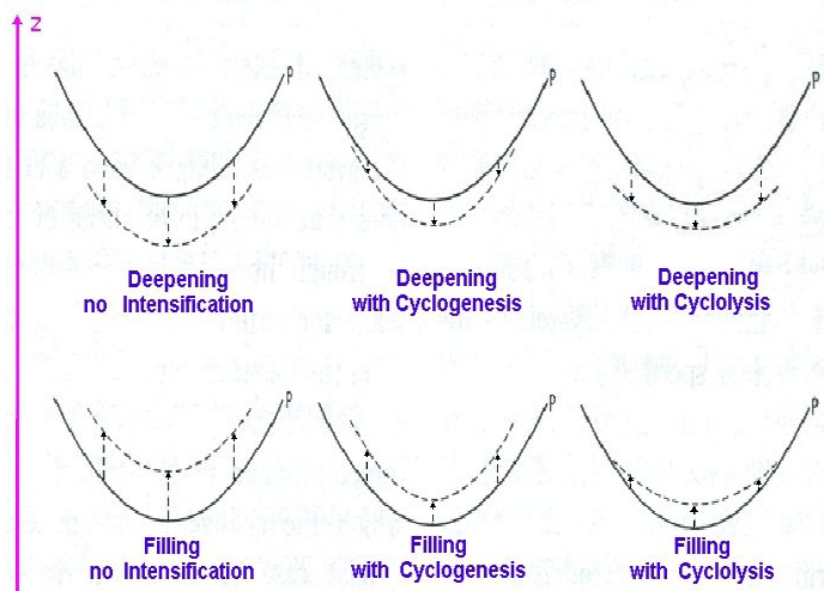

Fig. 1. Combinations between deepening/filling, and intensification/weakening (cyclogenesis/cyclolysis) at an isobaric surface.

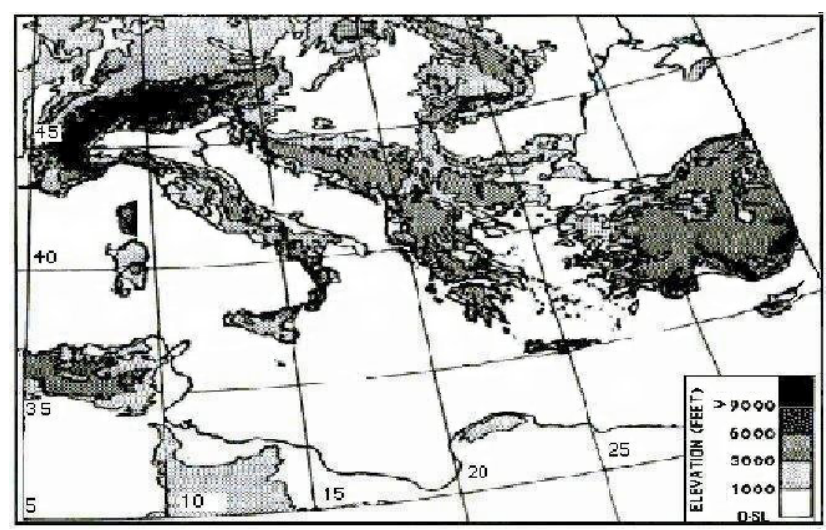

Fig. 2. Simplified topography map of the investigation area.

\section{Maximum deepening and intensification in the entire region}

Deepening refers to geopotential height drop at the center of the systems. Therefore, negative values are expected which in the study are expressed in gpm per $6 \mathrm{~h}$ (the time resolution). On the other hand, intensification is expressed by positive values, which are expressed in gpm per $100 \mathrm{~km}$ and $6 \mathrm{~h}$. Both parameters are characterized by J-shape frequency distributions (Fig. 3). Average values for the entire area are $-12 \mathrm{gpm} / 6 \mathrm{~h}$ and $1.4 \mathrm{gpm} / 100 \mathrm{Km} * 6 \mathrm{~h}$ for the maximum deepening and intensification respectively. Occurrence time of these parameters during the cyclone's life cycle is presented in Fig. 4, which is a double frequency distribution histogram. The cyclones which are considered in the figure, are originated inside the investigation area and not entering it. Both the maximum deepening and maximum intensification of 500-hPa cyclones occur at the early stages of their life cycle. Nevertheless, the relative frequency of cyclones that reach the maximum deepening for the first $6 \mathrm{~h}$ of their life cycle is higher than the relative frequency of the cyclones that reach the maximum intensification at the same period of time.
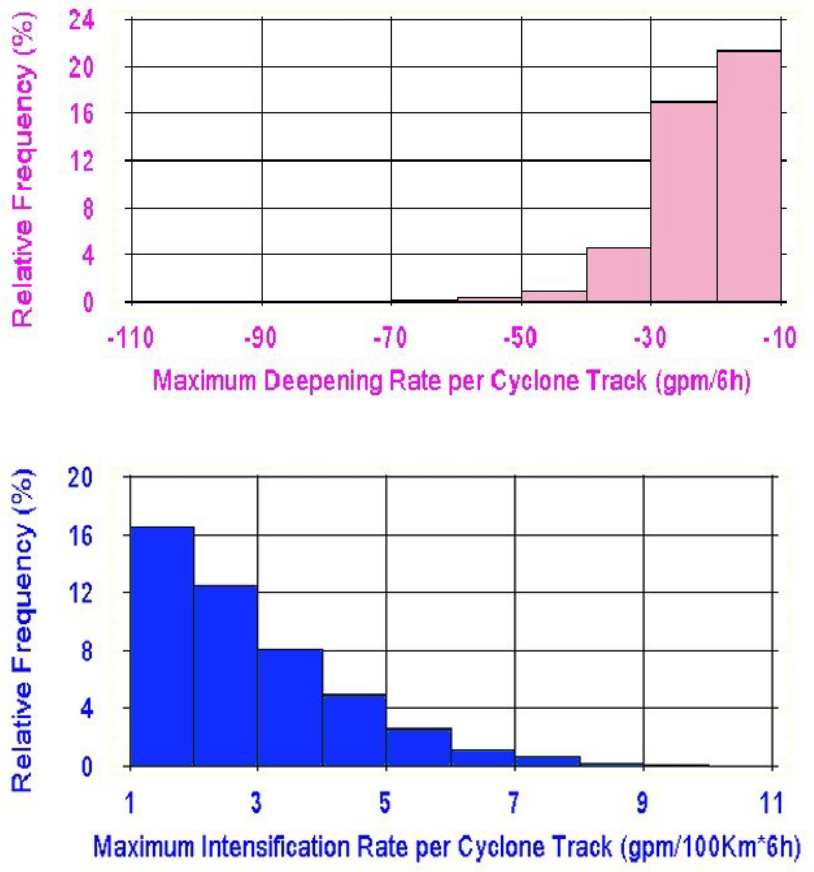

Fig. 3. Frequency distributions for maximum deepening (a) and intensification (b).

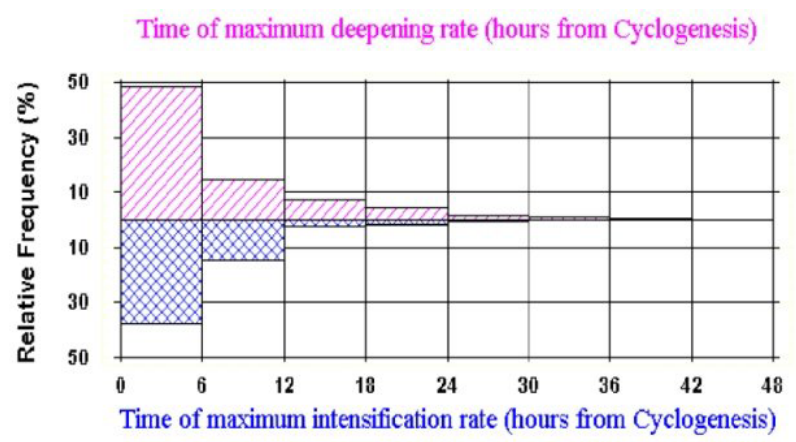

Fig. 4. Distribution comparison between maximum deepening and maximum intensification times.

\section{Spatial distributions of maximum deepening and in- tensification}

The spatial distribution of maximum deepening (Fig. 5a) shows that frequency mainly peaks around major cyclogenesis areas such as Turkey (Spanos et al., 2003), North Aegean Sea (Flocas and Karakostas, 1996), and the gulf of Genoa and the Adriatic Sea (Radinovic, 1987). On the other hand, maximum intensification (Fig. 5b) peaks over the west coasts of Italy (broader Genoa region) and Greece, over the east coast of Romania and over the Turkish highlands and the Panonian valley.

The broader Genoa and Turkey regions are both characterized by local frequency maxima for the maximum deepening and intensification (Fig. 5). A comparison of the cyclone populations at these maxima for both regions is presented in 

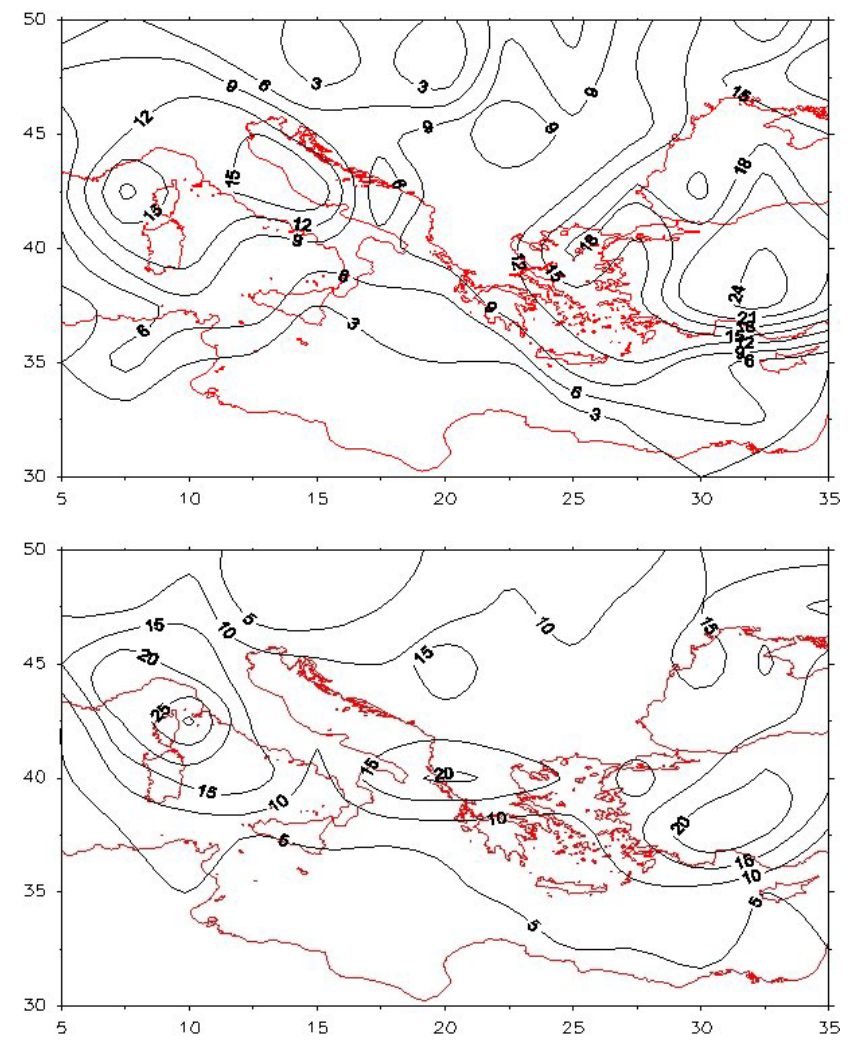

Fig. 5. Spatial distributions of maximum deepening (a) and intensification (b).

Table 1. It seems that most of the cyclones $(75 \%)$, which show the maximum deepening at Genoa region, reach their peak during the first $6 \mathrm{~h}$ of their life cycle. On the other hand only $15 \%$ of the cyclones, which show the maximum intensification at Genoa region, reach their peak during the first $6 \mathrm{~h}$. The opposite tendency is observed for the cyclones in the region of Turkey, although in this case, the difference in percentages is smaller. Although the Genoa and Antalya gulfs present a similar topography, the origin of cyclogenesis seems quite different. Cyclogenesis at the gulf of Genoa is triggered by the conservation of potential vorticity at the lee of the Alps and other processes are later involved. At the Antalya region cyclogenesis originates inland triggered by low-level instability and/or diabatic heating.

The variation of the spatial distribution of maximum intensification (Fig. 6) during warm period indicates a relationship of the process to instability, diabatic heating and probably to local circulations. At the early warm period, the process is influenced by the warm land-cool sea combination. Maximum Intensification peaks over land surrounded by sea. Figure $6 \mathrm{a}$ shows a number of local maxima over Corsica-Sardinia, the Greek peninsula and the interior of Asia Minor. At the middle warm period, the distribution peaks over northern Italy, especially over the south slopes of the Alps, over the Panonian valley, at the southern edge of the Italian boot and over the Greek peninsula. At the late warm period the process is influenced by the reverse phenomenon (warm sea-cool land)
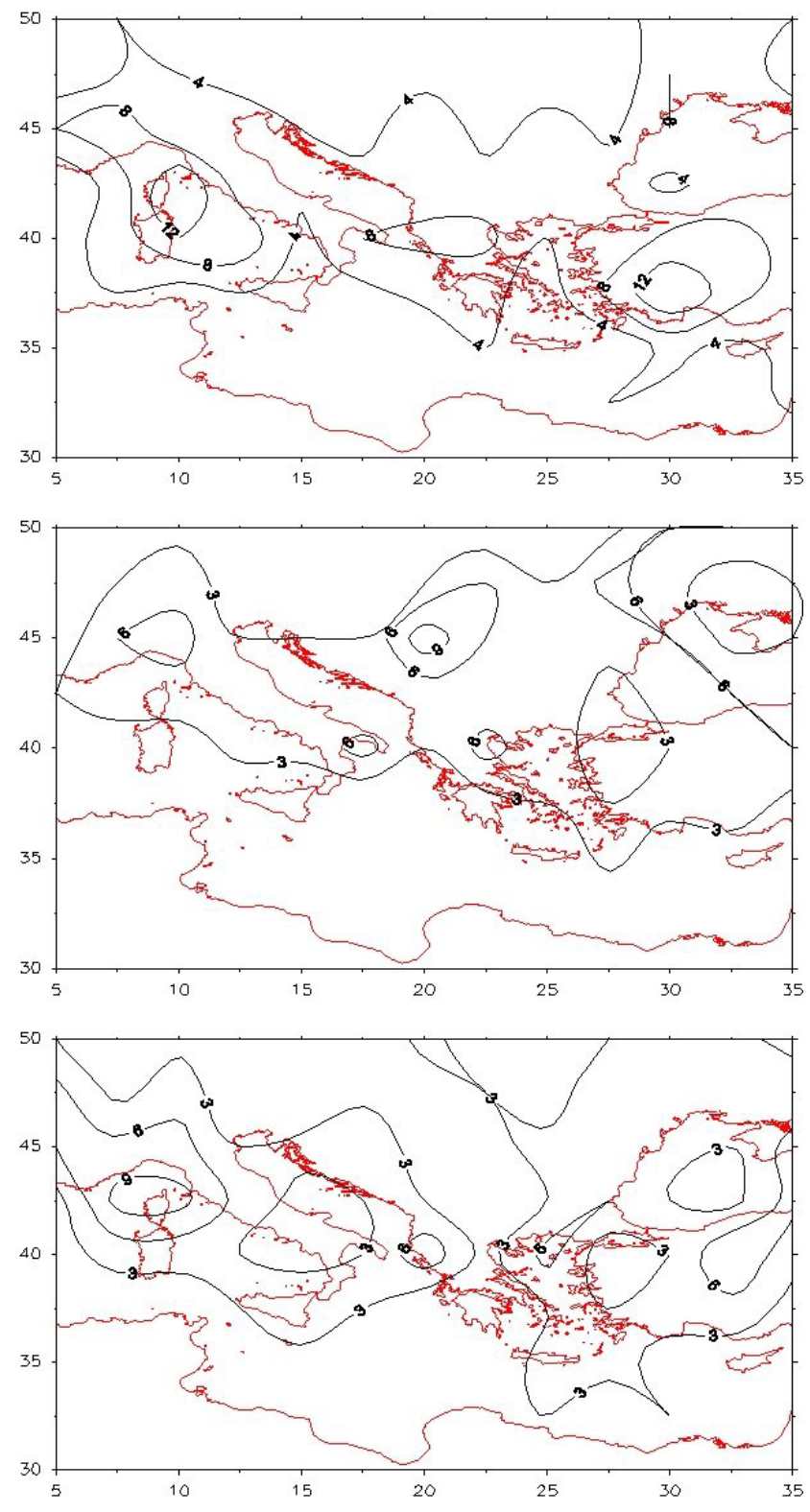

Fig. 6. Spatial distributions of occurrence frequency for maximum intensification during the (a) early (16 April-15 June), (b) middle (16 June-15 August) and (c) late (16 August-15 October) warm period.

and the frequency peaks over the gulf of Genoa, the north Aegean and the west coast of Greece. The high frequency at the northeast of Turkey is also an extension of a local maximum over southeast part of Black Sea.

\section{Concluding remarks}

The evidence, which is presented in this paper, suggests that the maximum deepening in the life cycle of a $500-\mathrm{hPa}$ cyclone is favored at the lee of mountain ranges such as the Alps and the Pindos or Rodope. The theoretical basis of this connection probably lies on the conservation of potential 
Table 1. Relative frequency comparison between Genoa and Turkey (at local maxima) for cyclone occurrence in the first $6 \mathrm{~h}$ of their life cycle.

\begin{tabular}{ccc}
\hline Parameter/Area & Max. Deepening in first 6 h & Max. Intensification in first 6 h \\
\hline Genoa & $75 \%$ & $15 \%$ \\
Turkey & $33 \%$ & $46 \%$ \\
\hline
\end{tabular}

vorticity in a northwest current. Maximum deepening also occurs inland, over elevated areas such as the southeast Turkey (Anatolia plateau). Overheated by the sun during warm period, this region modifies an unstable atmospheric environment, which probably enhances the cyclone deepening. Atmospheric instability plays a similar and/or parallel role in the enhancement of cyclone intensification at the region. The effect is also attributed to the frequency maximum over Panonian valley. Similar conclusions are drawn from the variation of frequency distribution during the advance of warm period. In this course, intensification maxima are coupled to warmer surfaces (instability sources) such as, land surface during early and middle warm period and sea surface during late warm period. Maximum intensification is also observed over coastlines such as the west coast of Italy, the west coast of Greece and the northwest coast of Black Sea. Coastlines are places where the Laplacian of thermal terms (instability, diabatic heating, thermal advection) in Sutcliffe's development increases (Metaxas, 1978). Deepening in the gulf of Genoa usually occurs earlier than intensification, while in Turkey the reverse is noticed. It seems that vorticity advection induced by the Alps is the primary factor for the Genoa Cyclones and other processes like instability and diabatic heating are later involved. On the other hand, the primary factor for Turkey Cyclones is instability and the other development factors follow.

Edited by: V. Kotroni and K. Lagouvardos Reviewed by: anonymous referee

\section{References}

Alberta, T. L., Colucci, S. J., and Davenport, J. C.: Rapid $500 \mathrm{mb}$ Cyclogenesis and Anticyclogenesis, Mon. Wea. Rev., 119, 11861204, 1991.

Bell, G. D. and Bosart, L. F.: A 15-year Climatology of northern hemisphere $500 \mathrm{mb}$ closed cyclone and anticyclone centers, Mon. Wea. Rev., 117, 2142-2163, 1989.

Flocas, H. A. and Karakostas, T. S.: Cyclogenesis over Aegean Sea: Identification and Synoptic Categories, Meteorol. Appl., 3, 5361, 1996.

Metaxas, D. A.: Evidence on the Importance of Diabatic Heating as Divergence Factor in the Mediterranean, Arch. Met. Geoph. Biokl. Ser A, 27, 69-80, 1978.

Parker, S. S., Hawes, J. T., Colucci, S. J., and Hayden, B. P.: Climatology of $500 \mathrm{mb}$ Cyclones and Anticyclones, 1950-1985, Mon. Wea. Rev., 117, 558-570, 1989.

Radinovic, D.: Mediterranean Cyclones and their Influence on the Weather and Climate, Program on Short and Medium Range Weather Prediction Research (PSMP), W.M.O. Sofia, No. 24, 132 pp, 1987.

Saucier, W. J.: Principles of Meteorological Analysis, University of Chicago Press, Chicago and London, 438pp., 1989.

Spanos, S., Maheras, P., Karacostas, T., and Pennas, P.: Objective Climatology of 500-hPa Cyclones in Central and East Mediterranean Region during Warm-Dry Period of the Year, Theor. Appl. Climatol., 75, 167-178, 2003.

Trigo, I. F., Davies, T. D., and Bigg, G. R.: Objective Climatology of Cyclones in the Mediterranean Region, J. Climate, 12, 16851696, 1999. 